Tanja Pilger

\title{
Erziehung im Leiden
}

Komposition und Theologie der Elihureden in Hiob 32-37

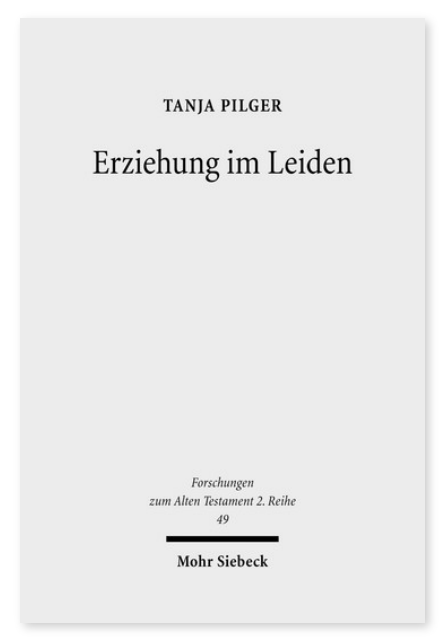

2010. X, 275 Seiten. FAT II 49

ISBN 978-3-16-151147-9

DOI 10.1628/978-3-16-151147-9

eBook PDF 74,00€

ISBN 978-3-16-150611-6

fadengeheftete Broschur 74,00€
Tanja Pilger legt Komposition und Theologie der Elihureden im Hiobbuch aufgrund der Analyse der Einzelreden dar. Die Komposition weist Fortschreibungen der Elihureden aus und berücksichtigt ihre theologischen Profile im Vergleich zur Dialogdichtung im Hiobbuch. Komposition und Theologie zeichnen den genuin theologischen Gehalt Elihus im Hiobbuch nach. Die Vorstellung der Erziehung im Leiden sowie der Befreiung des Leidenden durch Gott finden bei Elihu Gestalt. Dazu vermittelt ein Engel zwischen dem leidenden Menschen und Gott. Die von Hiob geforderte Gerechtigkeit Gottes greift Elihu auf und vertieft die Vorstellung von Gott als erhabenem und transzendentem Schöpfer wie die Geschöpflichkeit des Menschen. In den Elihureden hat eine erste theologische Auseinandersetzung mit der Hiobthematik stattgefunden.

Tanja Pilger Geboren 1978; Studium der Ev. Theologie und Jüdischen Studien in Münster, Jerusalem und Berlin; 2010 Promotion (im Fach Altes Testament) in Göttingen; seitdem Wissenschaftliche Mitarbeiterin für Altes Testament und ChristlichJüdische Studien an der Theologischen Fakultät der Humboldt-Universität zu Berlin.

Jetzt bestellen:

https://mohrsiebeck.com/buch/erziehung-im-leiden-9783161511479?no_cache=1

order@mohrsiebeck.com

Telefon: +49 (0)7071-923-17

Telefax: +49 (0)7071-51104 